\title{
Spatiotemporal variability of winter wheat phenology in response to weather and climate variability in China
}

\author{
Dengpan Xiao • Juana P. Moiwo • Fulu Tao • \\ Yonghui Yang • Yanjun Shen • Quanhong Xu • \\ Jianfeng Liu $\cdot$ He Zhang $\cdot$ Fengshan Liu
}

Received: 3 October 2013 / Accepted: 21 November 2013 /Published online: 3 December 2013

(C) Springer Science+Business Media Dordrecht 2013

\begin{abstract}
Weather and climate variability are predicted to impact food security by altering crop growth, phenology, and yield processes. Adaptation measures are critical for reducing future vulnerability of crop production to warming weather and climate variability. It is therefore vital to investigate the shifts in crop phenological processes in response to weather/climate variability. This study analyzes the trends in the dates of winter wheat (Triticum aestivum L.) phenology in relation to average temperature of different growth stage and the adaptation of the crop to weather/climate variability in China. The results suggest that the phenological phases of winter wheat have specific regional patterns in China. There are also significant shifts in the dates of winter wheat phenology and the duration of the growth stages in the investigated 30-year period of 1980-2009. While the date of sowing winter wheat delays, the dates of post-winter phenological phases (e.g., heading and maturity dates) advances in most areas of China. Detailed analysis shows that the changes in the phenological phases of winter wheat are strongly related to temperature trends. Temporal trends in phenological phases of winter wheat are similar in characteristics to corresponding trends in temperature. Although warming weather and climate variability is the main driver of the changes in winter wheat phenology, temperature is lower than before in most of the investigated stations during the period from heading to maturity - mainly the grain-filling stage. This is mainly due to the early heading and maturity dates, which in turn not only prolong growth
\end{abstract}

Electronic supplementary material The online version of this article (doi:10.1007/s11027-013-9531-6) contains supplementary material, which is available to authorized users.

D. Xiao $\cdot$ J. P. Moiwo $\cdot$ F. Tao $(\bowtie) \cdot$ H. Zhang $\cdot$ F. Liu

Institute of Geographical Sciences and Natural Resources Research, Chinese Academy of Sciences,

Beijing 100101, China

e-mail: taofl@igsnrr.ac.cn

D. Xiao $\cdot$ Q. Xu $\cdot$ J. Liu

Institute of Geographical Sciences, Hebei Academy of Sciences, Shijiazhuang 050011, China

D. Xiao $\cdot$ Y. Yang $\cdot$ Y. Shen

Center for Agricultural Resources Research, Institute of Genetics and Developmental Biology,

Chinese Academy of Sciences, Shijiazhuang 050021, China 
stages but also enhance productivity of winter wheat. This could be a vital adaptation strategy of winter wheat to warming weather with beneficial effects in terms of productivity.

Keywords Adaptation $\cdot$ Winter wheat $\cdot$ Phenology $\cdot$ Growth stage $\cdot$ Climate variability

\section{Introduction}

With warming weather and climate variability across the globe in the last half century or so (IPCC 2007), a significant warming is noted since the 1980s in China (Ding et al. 2006). Studies show that weather/climate variability affects the development and productivity of field crops and influences food security (Tingem and Rivington 2009; Misra 2013; Xiao and Tao 2013). Plant phenology, generally defined as the phasic process of plant cycle or timeline activities of plants (Lieth 1974), has a considerable history of scientific research (Menzel 2002; Chmielewski et al. 2004). Plant phenology is a plant growth progress driven largely by meteorological conditions (Menzel et al. 2006). Phenological change is among the most used indicators for variability of weather/climate and environmental conditions (Zheng et al. 2002; Estrella et al. 2009).

Observations of phenological processes are relative cost-effective and plant phenology responds to various meteorological and environmental factors. Exploration of global and planetary change suggests a close connect between plant phenology and weather/climate variability (Chmielewski et al. 2004; Xiao et al. 2013). Several studies show that spatiotemporal changes in plant phenological seasons in the northern hemisphere are mainly driven by warming weather and climate variability (Myneni et al. 1997; Diskin et al. 2012; Siebert and Ewert 2012; Xiao et al. 2013). Early phenological processes are noted in leafing and flowering of plants (Estrella et al. 2009). Crop phenology can be confounded by the effects of weather/climate conditions and agronomic factors such as cropping systems, cultivar choices, and soil conditions. Although the timing of farming operations is to some extent controlled by man, it is not completely independent of weather conditions (Craufurd and Wheeler 2009). Annual phases of crops such as heading, flowering, and maturity are strongly influenced by weather conditions (Hu et al. 2005; Tao et al. 2006; Estrella et al. 2009; Xiao et al. 2013).

The impact of weather/climate variability on crop productivity is demonstratedly measured by timing crop growth stages (Kelman and Dove 2009). A number of studies have focused on the relationship between change in plant phenology and weather/climate variability (Chmielewski et al. 2004). However, less remains known about the adaptation of crops to warming weather and climate variability and its mitigation effects on crop productivity and food security (Tao et al. 2006). In phenological changes, crops generally alter growth conditions and adapt to weather/climate variability to mitigate the effects of the changes (Xiao et al. 2013). It is therefore critical to investigate the shifts in crop phenological processes of adaptation to weather/climate variability in major crop production regions.

As the third main food crop (after rice (Oryza) and maize (Zea)), wheat (Triticum aestivum L.) is a traditionally, high-end cultivated crop in China. Winter wheat accounts for over $90 \%$ of China's wheat production. The prevailing soil and climatic conditions in China's arable lands are specifically suitable for winter wheat cultivation (Fig. 1). Because of winter dormancy and active summer growth, winter wheat is especially sensitive to weather/climate conditions (Xiao et al. 2013). Changes in winter wheat phenology are readily observed and directly monitored in conventional field experiments. The changes in the dates of phenological phases are widely used to assess the response of winter wheat to weather/climate variability (Stacks et al. 2010). 
In this study, the phenological phases of winter wheat is analyzed for the period 1981-2009 using field data collected from 82 agro-experimental stations across China (Fig. 1). The agroexperimental stations cover nearly all major winter wheat cultivation regions in China. The study primarily analyzes the spatiotemporal variability in phenological phases of winter wheat in the three decades spanning 1981-2009. The study further determines the phenological trends in winter wheat and temperature across China. The results of the study could enable farmers to either adapt the timing of cultivation to weather/climate variability or to adopt highyield cultivars under warming weather and climate variability.

\section{Data and methods}

\subsection{Data}

Data on winter wheat phenology are collected from 82 national agro-meteorological experimental stations for the period 1981-2009. The stations, operated by Chinese Meteorological Administration and provincial-level meteorological administrations, are fairly distributed across main winter wheat cultivation regions in China (Fig. 1). Enlisted agro-technicians in each station are used to record the dates of the main phonological phases during winter wheat season. The phenological processes include the dates of sowing, emergence, heading, anthesis, and maturity. Appendix S1 depicts a list of the stations along with their geographical (longitude, latitude, etc.) and phenological (stage, date, etc.) attributes.

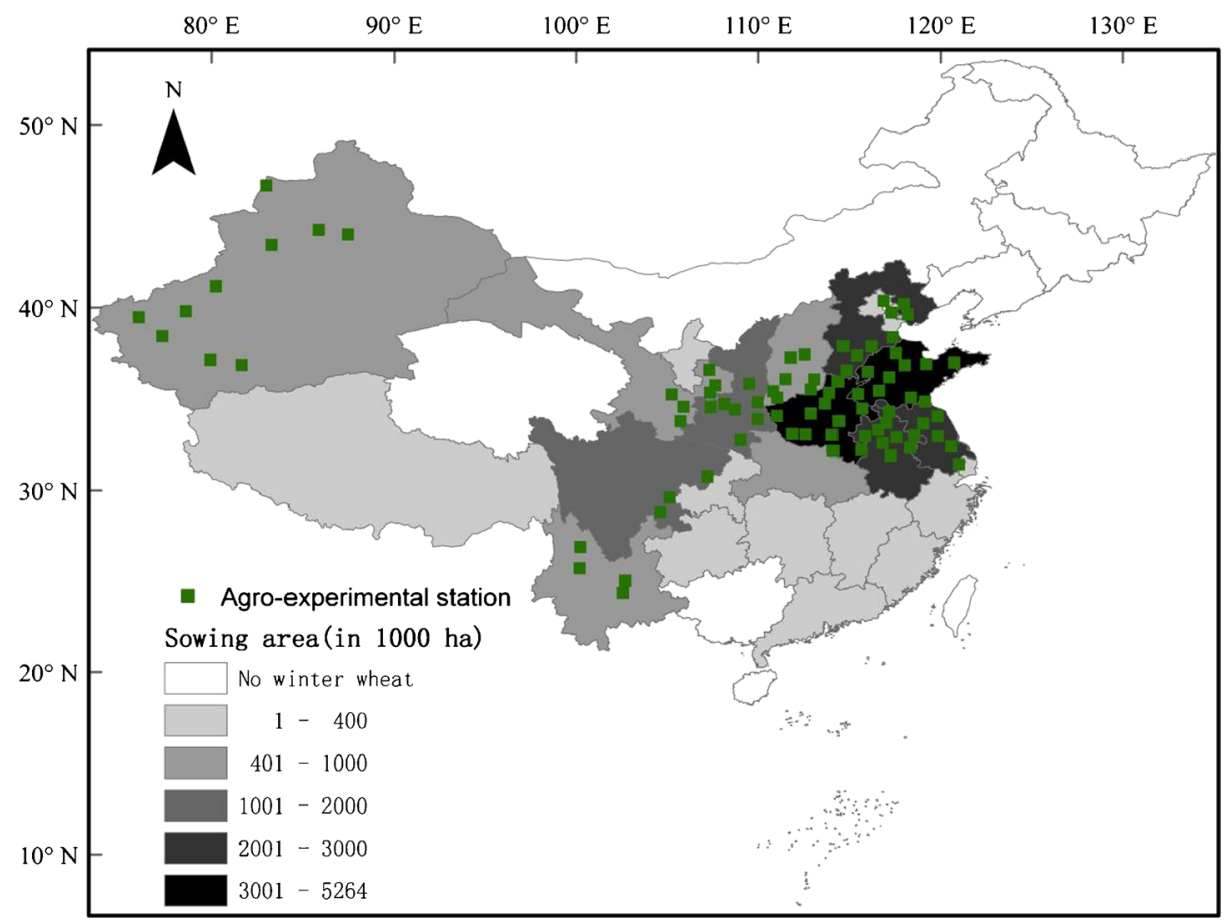

Fig. 1 A map of China depicting the locations of the agro-meteorological experimental stations where data are collected for the study 
Daily weather data (e.g., minimum, maximum, and mean temperature) for 1980-2009 are from a total of 756 ground-based meteorological stations across the country. Of the 756 meteorological stations, 58 are in the agro-meteorological stations. This implies that there are no nearby weather stations in 24 of the investigated agro-meteorological stations. For the 24 stations, daily weather data are estimated using the Thornton et al. (1997) method. The method is used to interpolate data from the 756 weather stations to the nearest $10-\mathrm{km}$ resolution. Using this method, daily average temperature is derived for each agrometeorological experimental station for the period 1980-2009.

\subsection{Methods}

In this study, the mean dates of sowing, heading, and maturity of winter wheat in 1980-2009 are first computed for each station. Then based on the results, the mean temperatures $\left(T_{\text {mean }}\right)$ of the three growth stages of sowing to heading (vegetative growth period, VGP), heading to maturity (reproductive growth period, RGP), and sowing to maturity (whole growth period, WGP) are separately computed for each station. Next, the mean of the field-observed temperatures ( $T^{\prime}$ mean $)$ of the three growth stages (VGP, RGP, and WGP) are calculated based on the observed sowing, heading, and maturity dates in each of the stations.

Using regression analysis, the trends in the phenological phases of winter wheat, the durations of the growth stages, and the corresponding average temperatures $\left(T_{\text {mean }}\right)$ are calculated for each station for the period 1981-2009. The time-variant trend of each variable is determined using the linear regression model:

$$
Y_{i, j}=k X_{i, j}+b
$$

where $Y_{i, j}$ is the observed phenological date in year $i$ and station $j ; k$ is the linear regression slope; $b$ is the slope intercept; and $X_{i, j}$ is the year. Then $i=1,2,3, \cdots, 29$ and $j=1,2,3, \cdots, 82$. In this study, statistical significance is determined using the two-tailed $t$ test analysis.

The sequential Mann-Kendall trend test (Sneyers 1975) is used to determine the relationship between the phenological phases and the mean temperatures of the corresponding growth stages. The sequential Mann-Kendall trend test gauges the start of a trend in a give sample $X_{1}$, $\cdots, X_{n}$ from a set of random variables $X$, based on ranked series of progressive and retrograde curves of the sample. The magnitudes $X_{i}$ of annual mean time series and $i=1, \cdots, n$ are compared by $X_{k}$, where $k=1, \cdots, i-1$. For each comparison, the number of cases $X_{i}>X_{k}$ is counted and denoted by $d_{k}$. The test statistic is given as:

$$
d_{k}=\sum_{1}^{k} n_{k} \quad(k=1,3, \cdots, n)
$$

which is normally distributed for a given mean of:

$$
E\left(d_{k}\right)=\frac{k(k-1)}{4}
$$

and variance of:

$$
\operatorname{Var}\left(d_{k}\right)=\frac{k(k-1)(2 k+5)}{72}
$$


The forward sequential values of the statistic $\mathrm{UF}_{k}$ are calculated as:

$$
U F_{k}=\frac{d_{k}-E\left(d_{k}\right)}{\sqrt{\operatorname{Var}\left(d_{k}\right)}} \quad(k=1, \cdots, n)
$$

and the backward sequence $\mathrm{UB}_{k}$ is calculated using the same equation, but in the reverse order of the data series.

In the two-sided trend test, a null hypothesis is accepted at $\alpha$ significance level if $\mathrm{UF}_{k} \leq$ $\mathrm{UF}_{k(1-\alpha / 2)}$, where $\mathrm{UF}_{k(1-\alpha / 2)}$ is the critical value of the standard normal distribution with a probability exceeding $\alpha / 2$. A positive $\mathrm{UF}_{k}$ denotes an upward trend whereas the reverse denotes a downward trend. In this study, $\alpha$ is set at 0.05 significance level. The sequential Mann-Kendall test detects the approximate time a trend starts from the intersection point of the forward and backward curves of the test statistic. If the intersection point is significant at $\alpha=$ 0.05 , then the critical point of change is at that period.

\section{Results}

\subsection{Spatiality of phenological phases}

Mean sowing date of winter wheat shows an obvious regional pattern for the period 1980 2009 (Fig. 2a). In China, winter wheat is generally sown from late September (DOY 260) to mid November (DOY 317). Sowing date occurs earlier with increasing latitude (Fig. 2a). Also mean heading date of winter wheat follows a clear regional pattern for the period 1980-2009. Heading is generally from late February (DOY 52) to late May (DOY 152) (Fig. 2b). Unlike sowing date, heading date significantly delays with increasing latitude (Fig. 2b). The spatial pattern of maturity date of winter wheat is plotted in Fig. 2c. Winter wheat generally matures in late April (DOY 115) to mid-July (DOY 197) and the date of maturity delays with increasing latitude (Fig. 2c).

There is a clear spatial pattern in the length of period of the growth stages for 1980-2009. As in Fig. 2d, the period from sowing to heading (VGP) is 110-245 days. Also, the period from heading to maturity (RGP) is 37-52 days (Fig. 2e). Whereas VGP increases with increasing latitude (Fig. 2d), RGP decreases with increasing latitude (Fig. 2e). The period from sowing to maturity (WGP) of winter wheat is 166-288 days. Like VGP, WGP increases with increasing latitude (Fig. 2f).

\subsection{Temporality of phenological phases}

The sowing date of winter wheat depends not only on climatic conditions but also on other factor including soil water content and farm management practices. Of the 82 data stations, there is a significant $(p<0.05)$ delay in sowing date in 23 stations. For 1980-2009, sowing date delays by up to 6.3 days per decade in the 23 stations and advances by up to 5.8 days per decade in four stations (Fig. 3a). As in Fig. 3b, heading date of winter wheat advances on average by up to 12.4 days per decade. The trend in early heading is significant trend for 72 stations. Similar to heading, early maturity of winter wheat is noted in most of the stations. However, the number of days of early maturity of winter wheat is less than number of days of early heading in the study area (Fig. 3c).

The advances or delays in phenological phases of winter wheat correspond with the durations of the different growth stages. As depicted in Fig. 3d, the time from sowing to 


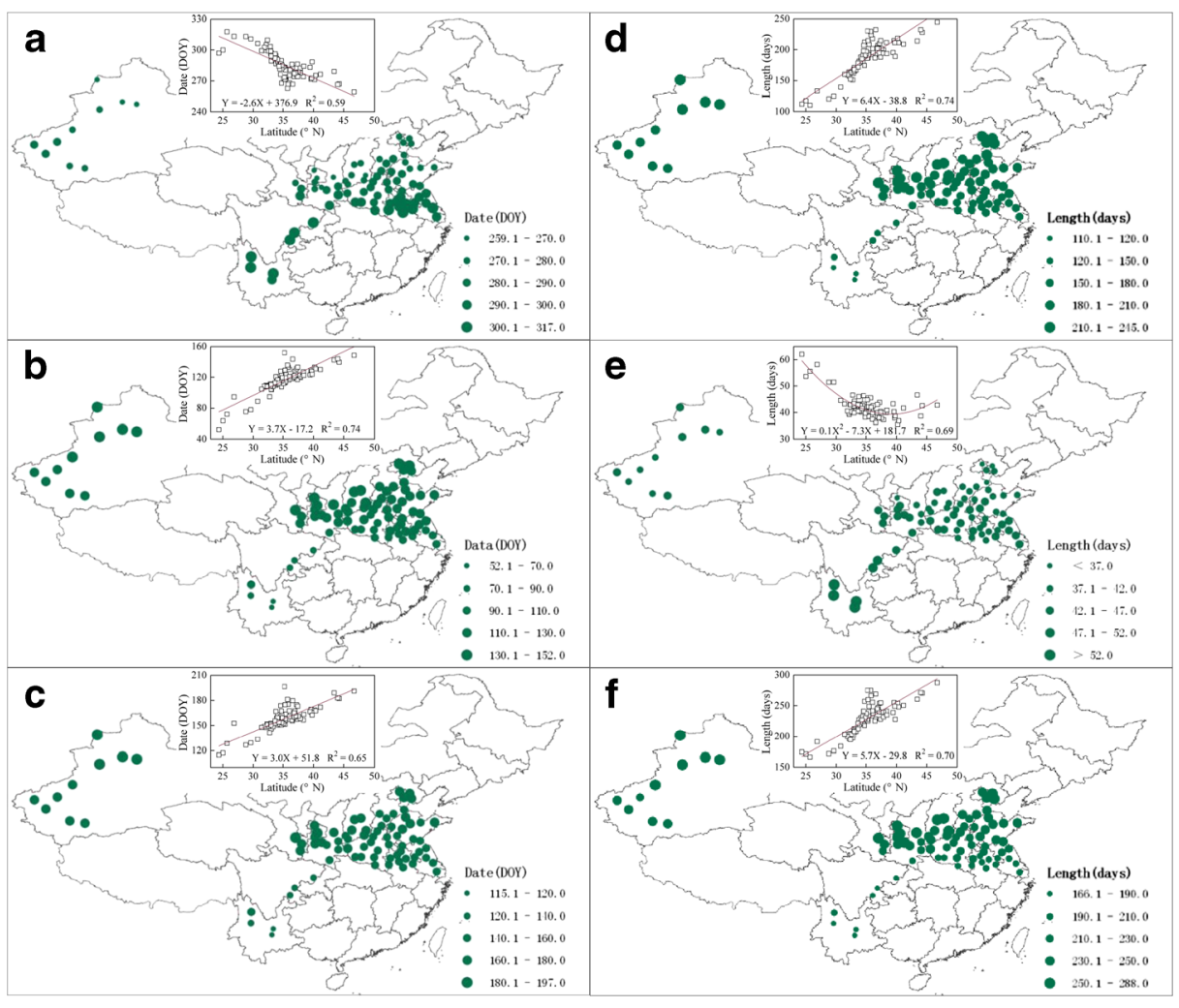

Fig. 2 Plots of mean dates of sowing (a), heading (b), and maturity (c) along with the lengths of time for the periods from sowing to heading (d), heading to maturity (e), and sowing to maturity (f) of winter wheat in the study area

heading (VGP) shortens in most of the stations, significant $(p<0.05)$ for 45 stations. Conversely, the time from heading to maturity (RGP) slightly prolongs on average by up to 6.0 days per decade in most of the stations, significant $(p<0.05)$ for 37 stations (Fig. 3e). As in Fig. 3f, the time from sowing to maturity (WGP) shortens on average by up to 11.3 days per decade in a large number of the stations, also significant $(p<0.05)$ for 30 stations.

\subsection{Phenology and temperature}

The sequential Mann-Kendall test is used to graphically illustrate the trends in heading and maturity dates and in mean annual temperatures $\left(T_{\text {mean }}\right)$ for the period from sowing to heading (VGP) and sowing to maturity (WGP) in 1981-2009.

As shown in Fig. 4a, c, there is an insignificant delay in the dates of heading and maturity in 1981-1988. However, the dates of heading and maturity start occurring early in 1989 and reach a significant trend in 1999. Concurrently, abrupt early heading and maturity are noted in 1996 (Fig. 4a, c). By contrast, average temperature trends ( $\left.T_{\text {mean }}\right)$ during VGP and WGP show an insignificant decline in the investigated stations in 1981-1988. After 1989, mean temperatures for both VGP and WGP start increasing, reaching a significant trend in 1999 (Fig. 4b, d). Like the dates of heading and maturity, $T_{\text {mean }}$ for VGP and WGP abruptly increases in 1996 (Fig. 4b, d). This suggests that changes in phenological phases of winter 


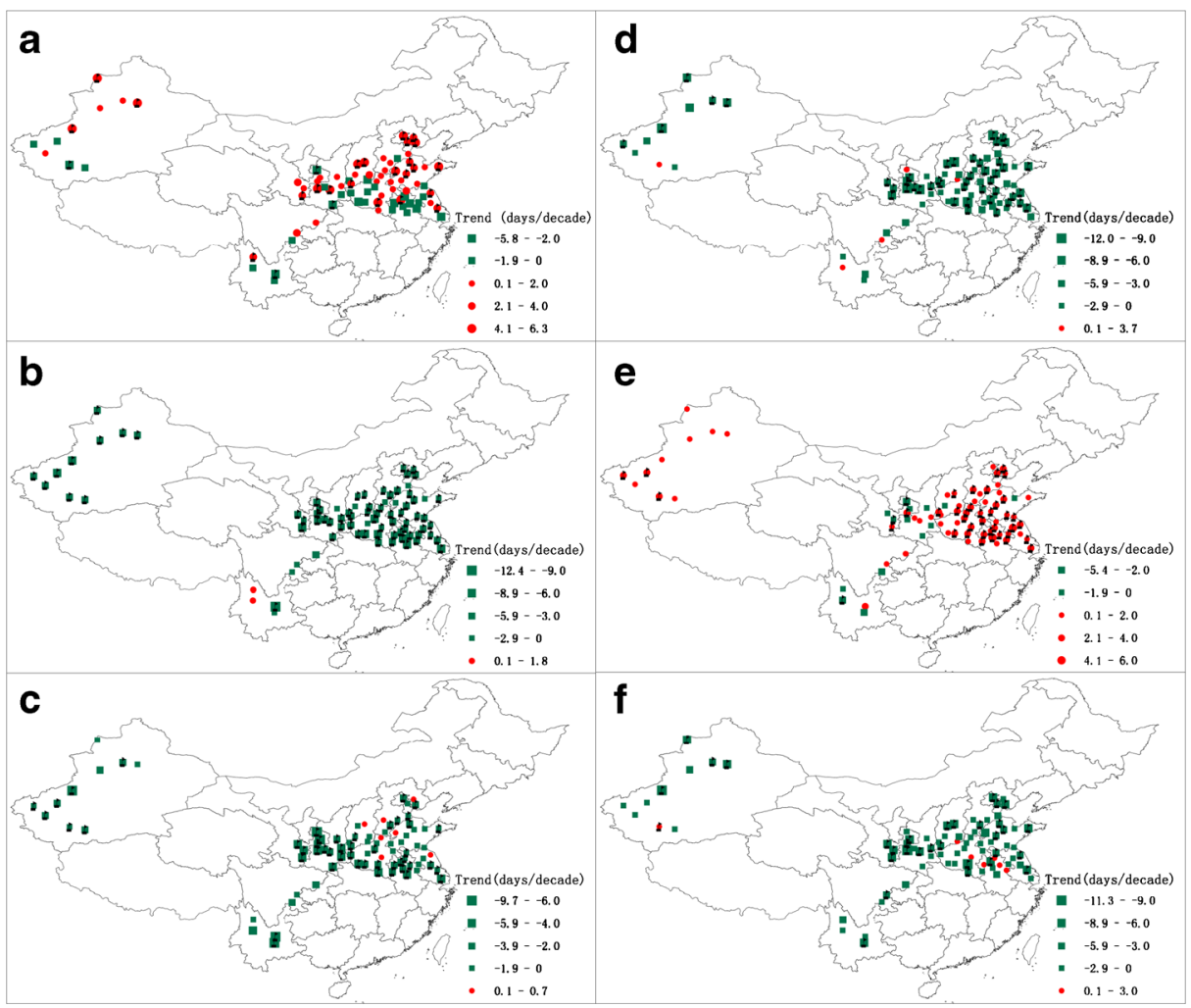

Fig. 3 Plots of the trends in sowing date (a), heading date (b), and maturity date (c) along with the length of time for the periods from sowing to heading (d), heading to maturity (e), and sowing to maturity (f) of winter wheat in China. Note that stations with significant trend at $p<0.05$ are flagged in the plots

wheat are strongly related to temperature trends. The study shows that temporal trends in phenological phases of winter wheat are similar in characteristics to those in temperature.

In the stations, early mean date of heading (by 4.2 days per decade) is mainly after 1989 (Fig. 5a). Also, mean temperature $\left(T_{\text {mean }}\right)$ for VGP significantly increases (by $0.6{ }^{\circ} \mathrm{C}$ per decade) in 1989-2009 (Fig. 5a). The trends in mean heading date and the corresponding temperature from sowing to heading (Fig. 5a) are similar to the trends in mean maturity date and the corresponding temperature from sowing to maturity (Fig. 5b). As depicted in Fig. 6, the mean dates of heading and maturity of winter wheat are significantly correlated respectively with $T_{\text {mean }}$ of RGP and WGP. The results suggest that phenological changes in winter wheat in China are mainly driven by changes in temperature.

\subsection{Adaptation to warming climate}

Winter wheat is sensitive to temperature change. Temperature rise in the past three decades has led to changes in the phenological processes of winter wheat. Weather/climate variability affects crop phenological processes, causing shifts in phenological dates and durations. Observed changes in phenological phases or growth stages of winter wheat are tied to changes in temperatures.

$T_{\text {mean }}$ for VGP, calculated from mean sowing and heading date, increases by up to $1.16^{\circ} \mathrm{C}$ (Fig. 7a). For all the investigated stations, $T_{\text {mean }}$ for VGP increases by $0.59{ }^{\circ} \mathrm{C}$ per decade in 

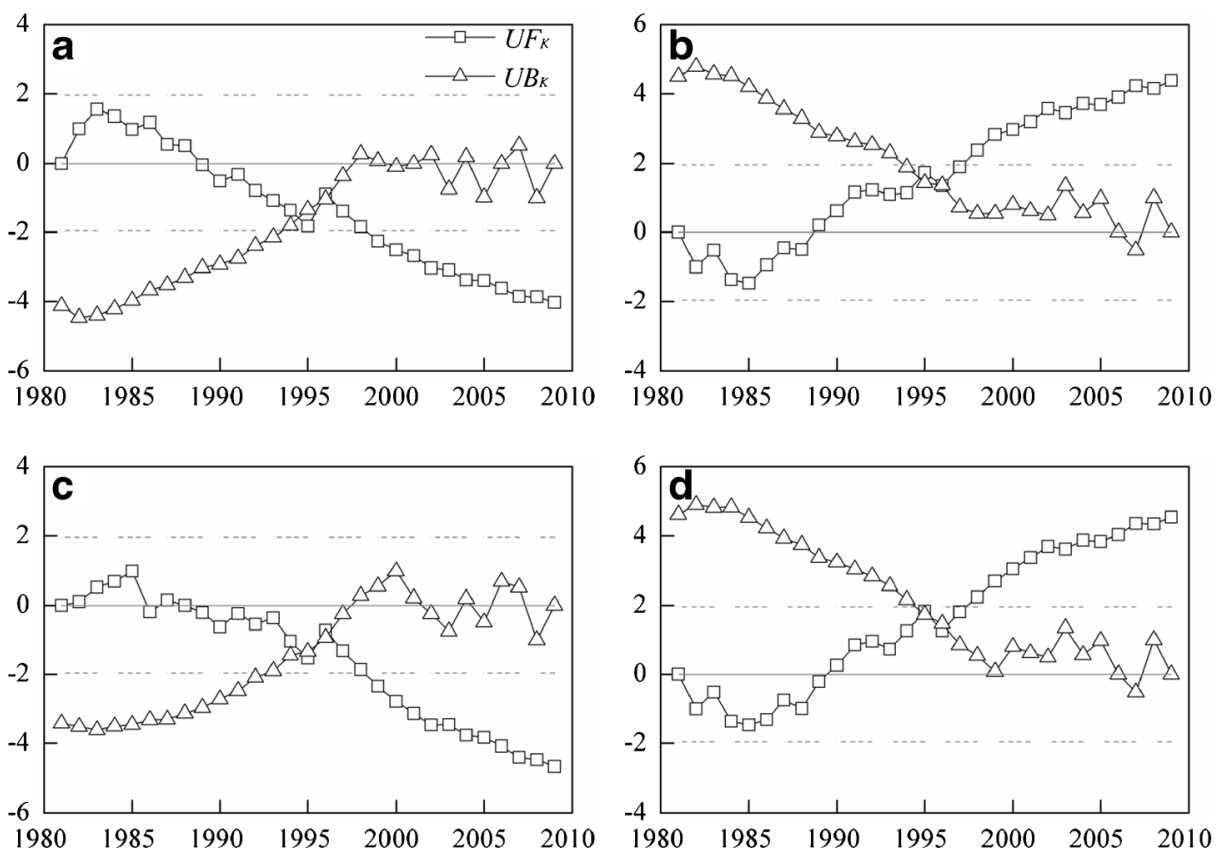

Fig. 4 Sequential Mann-Kendall test for heading date (a), mean temperature for the period from sowing to heading (b), maturity date (c), and mean temperature for the period from sowing to maturity (d). Dashed horizontal lines represent critical values corresponding to the $95 \%$ confidence interval

1981-2009 (Fig. 7a). Due to earlier heading date, however, the actual mean temperature $\left(T^{\prime}\right.$ mean, based on the observed sowing and heading date) for VGP increases by only $0.36{ }^{\circ} \mathrm{C}$ per decade (Fig. 7b). Similar to VGP, $T_{\text {mean }}$ for RGP (calculated from mean heading and maturity date) increases in all the stations, and significantly in 42 stations (Fig. 7c). However, actual $T$ mean (calculated from observed sowing and heading date) increases in 52 stations, and significantly in only 13 stations (Fig. 7d). This is largely due to early heading and maturity dates in the stations.

For the overall average of the investigated stations, $T_{\text {mean }}$ increases by $0.54{ }^{\circ} \mathrm{C}$ per decade in VGP in 1981-2009 (Fig. 7c). However, $T_{\text {mean }}^{\prime}$ only increases by $0.10{ }^{\circ} \mathrm{C}$ per decade (Fig. $7 \mathrm{~d}$ ). The above findings suggest that the early heading and maturity dates of winter wheat are due to warming weather and climate variability. Early heading and maturity due to temperature rise in actual growth stages are less than that in calculated growth stages from mean phenological dates in 1981-2009. This is a vital winter wheat adaptation strategy to weather/climate variability in the study area.

\section{Discussions}

Spatiotemporal variations in weather/climate conditions affect plant phenological processes (Menzel et al. 2006). Although soil conditions in most regions of China are suitable for winter wheat cultivation, wheat phenology significantly varies with climatic conditions (Xiao et al. 2013). In spite of farming practices soil conditions, decreasing temperature with increasing latitude from south to north China favor early sowing while delaying heading and maturity of 

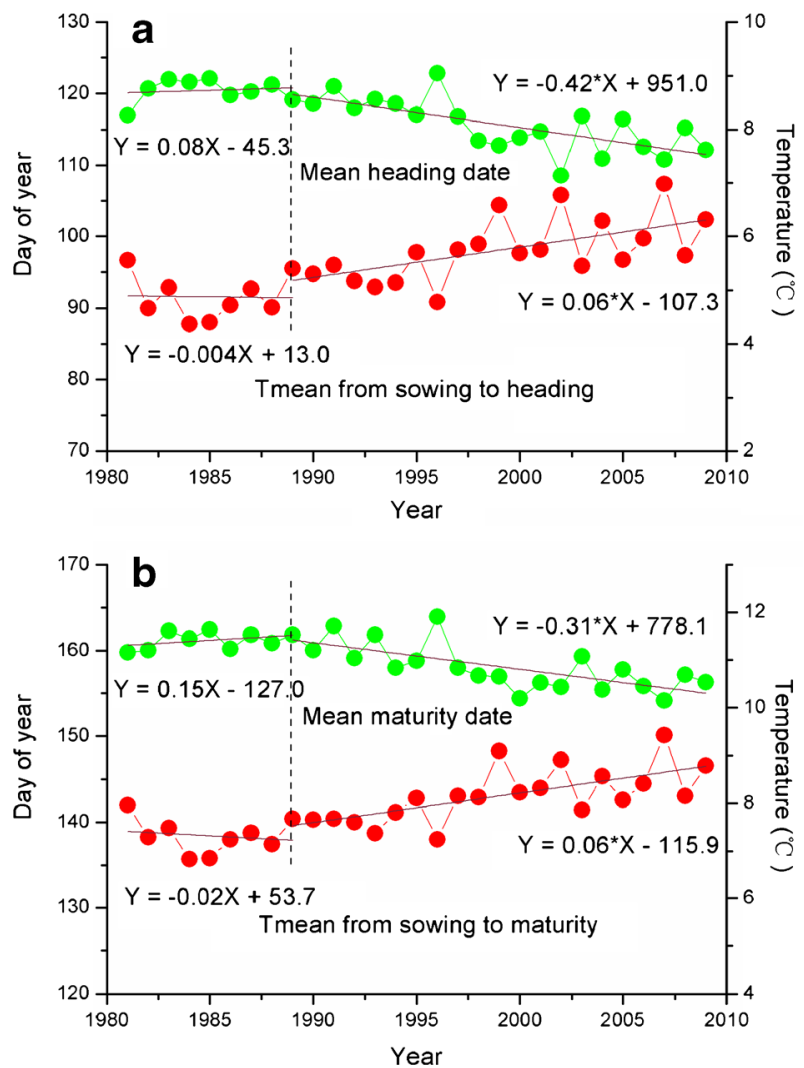

Fig. 5 Plots of the trends in mean date of winter wheat heading versus mean temperature for the period from sowing to heading (a), and mean date of winter wheat maturity versus mean temperature for the period from sowing to maturity (b) in China. $* p<0.05$ denotes significant trend

winter wheat. As a result, the durations of the growth stages vary with weather/climatic variability. While the duration from sowing to heading and sowing to maturity increases with increasing latitude, those from heading to maturity decreases with increasing latitude across China.

The results of our study show significant changes in phenological phases (e.g., sowing, heading and maturity dates) of winter wheat across China in the last three decades. Sowing depends not only on weather/climatic conditions but also on other factor such as soil water content and farm management practices (Moradi et al. 2013). For the past three decades, the date of sowing of winter wheat delays in most of the data stations. Xiao et al. (2013) also noted that delay of summer maize harvest is the main reason for the delay in sowing winter wheat in the wheat/maize double cropping system in the North China Plain. As winter wheat should sufficiently grow before dormancy sets in, warming weather delay dormancy and prolong active growth.

It is noted that the dates of the growth stages after winter (e.g., heading and maturity) occur early in most of the stations. Detailed analysis shows that the changes in the dates of heading and maturity correspond with temperature change in the study area. A significant advance is noted in the dates heading and maturity after 1989. This is also the period with the highest temperature rise in the study area. Although winter wheat responds to temperature via 

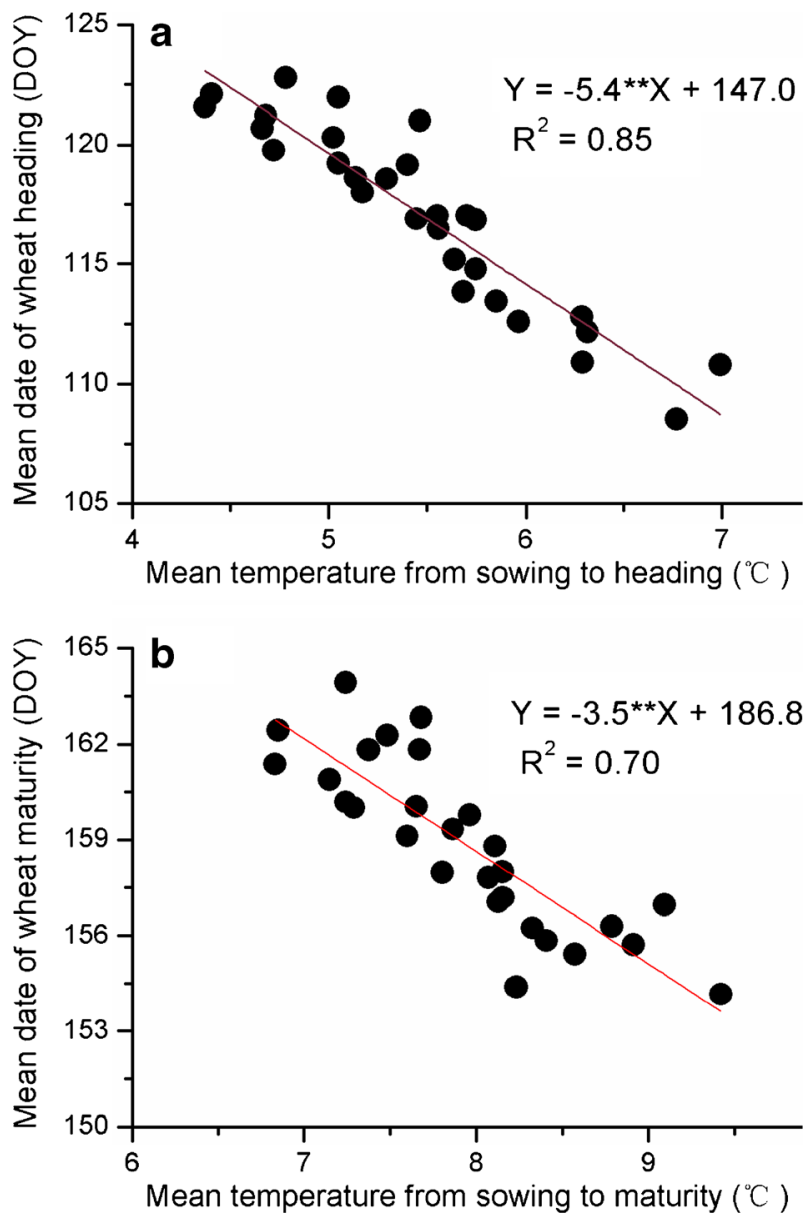

Fig. 6 Plots of the correlations between mean date of winter wheat heading versus mean temperature for the period from sowing to heading (a), and mean date of winter wheat maturity versus mean temperature for the period from sowing to maturity (b) in China

processes such as intrinsic development and vernalization (Porter and Gawith 1999), the timing of phenological phases such as heading and maturity is a reliable indicator for crop response to weather/temperature variability (Van Bussel et al. 2011). This suggests that warming weather favor early heading and maturity of winter wheat. This observation is in agreement with that of Xiao et al. (2013), that temperature rise (instead of cultivar shift) in the past several decades is the main cause of early maturity and shifts in other phenological phases of winter wheat.

Adaptation is critical for mitigating future vulnerability of crop production to weather/ climate variability (Misra 2013). Due to early heading and maturity, temperature rise during winter wheat season (calculated from mean heading and maturity dates) is less than that during the growth stages (calculated from observed phenological dates). Also due to early heading, grain-filling now occurs under lower temperatures than before. This in turn prolongs the length of time from heading to maturity (RGP). This may be a main reason that the duration from heading to maturity is slightly prolonged in most of the investigated stations. In addition, dry 

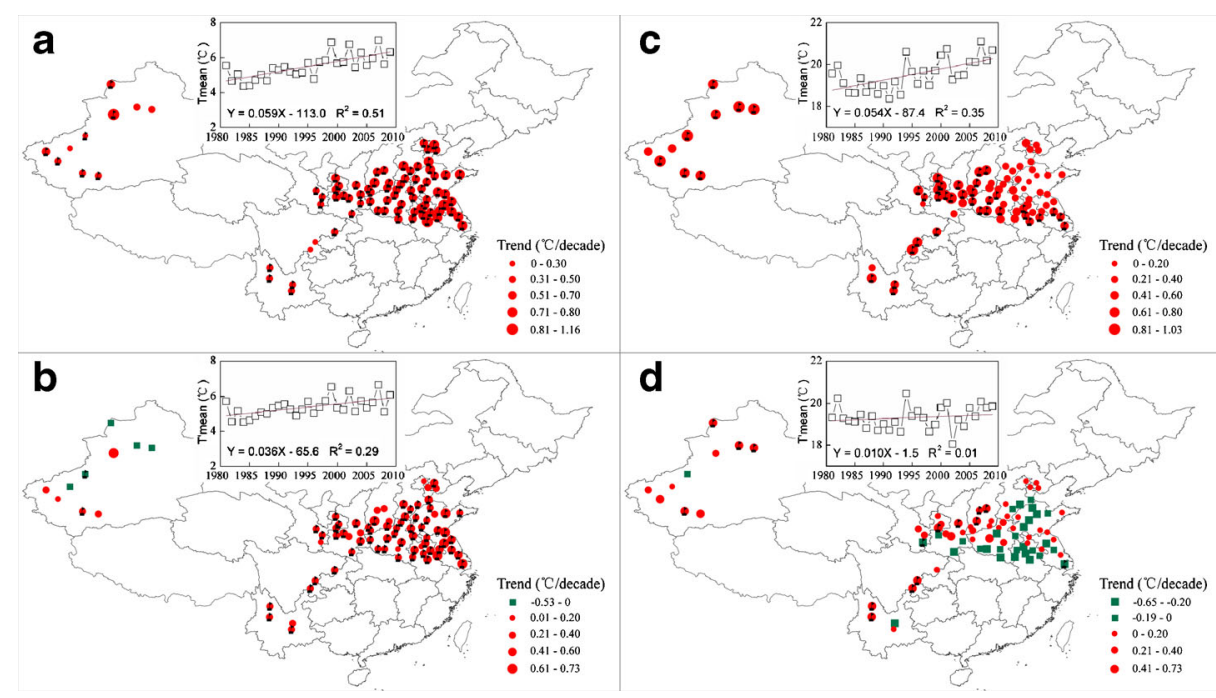

Fig. 7 Plots of the mean temperature for the period from sowing to heading calculated from mean sowing and heading date (a), mean temperature for the period from sowing to heading calculated from observed sowing and heading date in each year (b), mean temperature for the period from heading to maturity calculated from mean heading and maturity date (c), and mean temperature for the period from heading to maturity calculated from observed heading and maturity date in each year (d). Note that stations with significant trend at $p<0.05$ are flagged in the plots

grain weight (quantified as the product of time and grain-filling rate) increases linearly with the duration of grain-filling (Biscoe and Gallagher 1977; Xiao and Tao 2013). Thus, prolonged RGP (a critical yield formation stage) is potentially beneficial for high wheat productivity (Xiao et al. 2013). This is a useful adaptation strategy of winter wheat to warming weather and climate variability.

\section{Conclusions}

This study analyzes the shifts in the dates of winter wheat phenology in relation to weather/ climate variability during 1981-2009 in China. The study notes the start of early heading and maturity in 1989. This is also the starting period of temperature rise in the country. The study suggests that warming weather and climate variability is the main cause of the shifts in the dates of winter wheat phenology in China. Early dates of heading and maturity prolong the growth stages, which in turn result in high winter wheat productivity. This is a critical adaptation strategy of winter wheat to warming weather and climate variability in the study area.

The changes in the dates of crop phenology directly affect the processes of crop development, yield formation, and more importantly food security. Monitoring the response of crop development and phenology to weather/climate variability is therefore important for sustainable food security. This study adds further insight to crop performance monitoring process. The results further deepen our current insights into the impacts of weather/climate variability on future crop production and food security trends. The additional knowledge acquire from these insights could strengthen our ability to develop adaptable crop cultivars to warming weather and climate variability for sustainable food production/security to meet the food demands of the rapidly growing world population. 
Acknowledgments This study is supported by the National Science Foundation of China (Project No. 41071030), the Science and Technology Strategic Pilot Project of Chinese Academy of Sciences (Project No. XDA05090308), the National Key Program for Developing Basic Sciences in China (Project No. 2010CB950902), and Science Foundation of Hebei Academy of Sciences (Project No. 13123). We acknowledge the invaluable comments of the anonymous reviewers during the manuscript stage.

\section{References}

Biscoe PV, Gallagher JN (1977) Weather, dry matter production and yield. In: Land JJ, Cutting CV (eds) Environmental effects on crop physiology. Academic, London, pp 75-100

Chmielewski FM, Müller A, Bruns E (2004) Climate changes and trends in phenology of fruit trees and field crops in Germany, 1961-2000. Agric For Meteorol 121:69-78

Craufurd PQ, Wheeler TR (2009) Climate change and the flowering time of annual crops. J Exp Bot 60:2529-2539

Ding YH, Ren GY, Shi GY, Gong P, Zheng XH, Zhai PM, Zhang DE, Zhao ZC, Wang SW, Wang HJ, Luo Y, Chen DL, Gao XJ, Dai XS (2006) National assessment report of climate change (I): climate change in China and its future trend. Adv Clim Chang Res 2:3-8 (in Chinese with English abstract)

Diskin E, Proctor H, Jebb M, Sparks T, Donnelly A (2012) The phenology of Rubus fruticosus in Ireland: herbarium specimens provide evidence for the response of phenophases to temperature, with implications for climate warming. Int J Biometeorol 56:1103-1111

Estrella N, Sparks TM, Menzel A (2009) Trends and temperature response in the phenology of crops in Germany. Global Change Biol 13:1737-1747

Hu Q, Weiss A, Feng S, Baenziger PS (2005) Earlier winter wheat heading dates and warmer spring in the US Great Plains. Agric For Meteorol 135:284-290

IPCC (2007) Climate change 2007: synthesis report. Inter-governmental Panel on Climate Change. Cambridge University Press, Cambridge

Kelman WM, Dove H (2009) Growth and phenology of winter wheat and oats in a dual-purpose management system. Crop Pasture Sci 60:921-932

Lieth H (1974) Phenology and seasonality modeling. Springer, Berlin

Menzel A (2002) Phenology: its importance to the global change community. Clim Chang 54:379-385

Menzel A, Sparks TH, Estrella N et al (2006) European phenological response to climate change matches the warming pattern. Glob Chang Biol 12:1969-1976

Misra AK (2013) Climate change impact, mitigation and adaptation strategies for agricultural and water resources, in Ganga Plain (India). Mitig Adapt Strateg Glob Chang 18:673-689

Moradi R, Koocheki A, Nassiri Mahallati M, Mansoori H (2013) Adaptation strategies for maize cultivation under climate change in Iran: irrigation and planting date management. Mitig Adapt Strateg Glob Change 18:265-284

Myneni RB, Keeling CD, Tucker CJ, Asrar G, Nemani RR (1997) Increased plant growth in the Northern High Latitudes from 1981 to 1991. Nature 386:698-702

Porter JR, Gawith M (1999) Temperatures and the growth and development of wheat: a review. Eur J Agron 10:23-36

Siebert S, Ewert F (2012) Spatio-temporal patterns of phenological development in Germany in relation to temperature and day length. Agric For Meteorol 152:44-57

Sneyers R (1975) Sur l'analyse statistique des series d'observations, Tech. Note, 194, WMO, Geneva, p. 9-12

Stacks WJ, Deryng D, Foley JA, Navin R (2010) Crop planting dates: an analysis of global patterns. Glob Ecol Biogeogr 19:607-620

Tao FL, Yokozawa M, Xu YL, Hayashi Y, Zhang Z (2006) Climate changes and trends in phenology and yields of field crops in China 1981-2000. Agric For Meteorol 138:82-92

Thornton P, Running S, White M (1997) Generating surfaces of daily meteorological variables over large regions of complex terrain. J Hydrol 190:214-251

Tingem M, Rivington M (2009) Adaptation for crop agriculture to climate change in Cameroon: turning on the heat. Mitig Adapt Strateg Glob Chang 14:153-168

Van Bussel LGJ, Ewert F, Leffelaar PA (2011) Effects of data aggregation on simulations of crop phenology. Agric Ecosyst Environ 142:75-84

Xiao DP, Tao FL (2013) Contributions of cultivars, management and climate change to winter wheat yield in the North China Plain in the past three decades. Eur J Agron. doi:10.1016/j.eja.2013.09.020

Xiao DP, Tao FL, Liu YJ, Wang M, Liu FS, Zhang S, Zhu Z (2013) Observed changes in winter wheat phenology in the North China Plain for 1981-2009. Int J Biometeorol 57:275-285

Zheng JY, Ge QS, Hao ZX (2002) Impacts of climate warming on plants phenophases in China for the last 40 years. Chin Sci Bull 47:1826-1831 